\title{
Authentication of Electromagnetic Interference Removal in Johnson Noise Thermometry
}

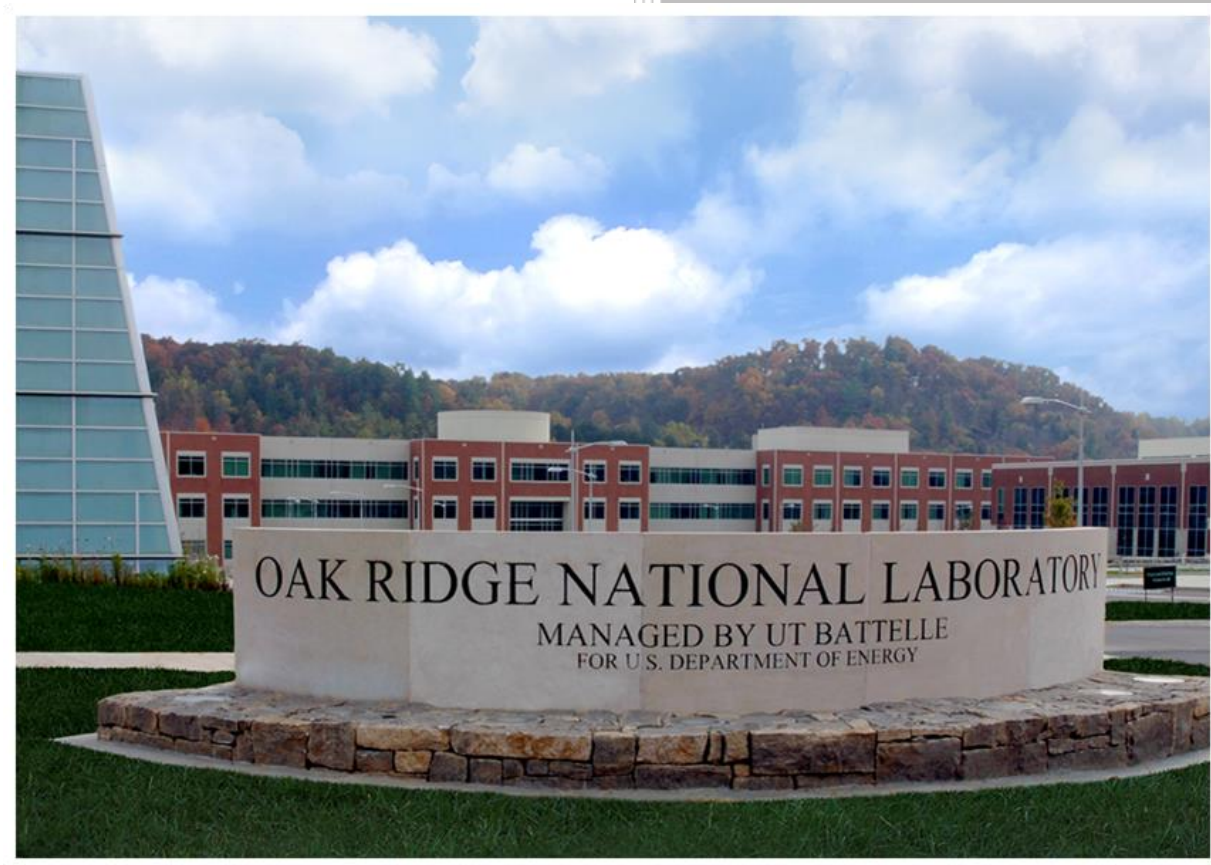

N. Dianne Bull Ezell Charles L. Britton Jr. Michael Roberts

January 2017 


\title{
DOCUMENT AVAILABILITY
}

Reports produced after January 1, 1996, are generally available free via US Department of Energy (DOE) SciTech Connect.

Website http://www.osti.gov/scitech/

Reports produced before January 1, 1996, may be purchased by members of the public from the following source:

\author{
National Technical Information Service \\ 5285 Port Royal Road \\ Springfield, VA 22161 \\ Telephone 703-605-6000 (1-800-553-6847) \\ TDD 703-487-4639 \\ Fax 703-605-6900 \\ E-mail info@ntis.gov \\ Website http://classic.ntis.gov/
}

Reports are available to DOE employees, DOE contractors, Energy Technology Data Exchange representatives, and International Nuclear Information System representatives from the following source:

Office of Scientific and Technical Information

PO Box 62

Oak Ridge, TN 37831

Telephone 865-576-8401

Fax 865-576-5728

E-mail reports@osti.gov

Website http://www.osti.gov/contact.html

This report was prepared as an account of work sponsored by an agency of the United States Government. Neither the United States Government nor any agency thereof, nor any of their employees, makes any warranty, express or implied, or assumes any legal liability or responsibility for the accuracy, completeness, or usefulness of any information, apparatus, product, or process disclosed, or represents that its use would not infringe privately owned rights. Reference herein to any specific commercial product, process, or service by trade name, trademark, manufacturer, or otherwise, does not necessarily constitute or imply its endorsement, recommendation, or favoring by the United States Government or any agency thereof. The views and opinions of authors expressed herein do not necessarily state or reflect those of the United States Government or any agency thereof. 
Electrical and Electronics Systems Research

\section{AUTHENTICATION OF ELECTROMAGNETIC INTERFERENCE REMOVAL JOHNSON NOISE THERMOMETRY}

N. Dianne Bull Ezell Charles L. Britton Jr. Michael Roberts

Date Published: January 2017

Prepared by OAK RIDGE NATIONAL LABORATORY

Oak Ridge, TN 37831-6283 managed by

UT-BATTELLE, LLC for the US DEPARTMENT OF ENERGY under contract DE-AC05-00OR22725 



\section{CONTENTS}

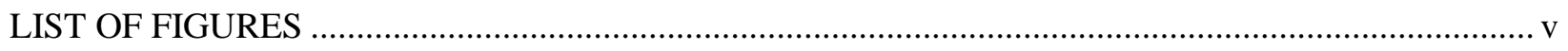

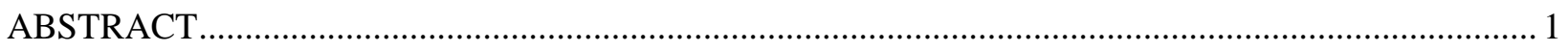

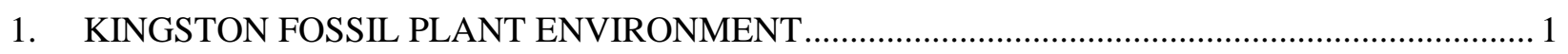

2. SOURCES OF ELECTROMAGNETIC INTERFERENCE AND ITS IMPACT ........................... 1

3. ELECTROMAGNETIC INTERFERENCE ENVIRONMENT AT KINGSTON FOSSIL

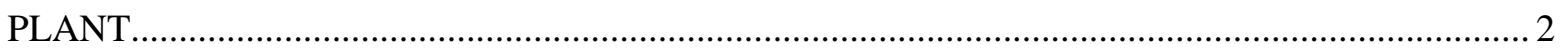

4. ELECTROMAGNETIC INTERFERENCE SPECTRAL RESULTS ..........................................4

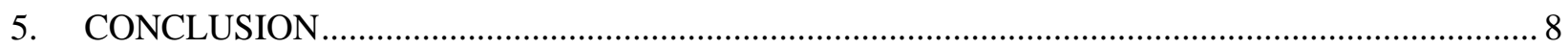

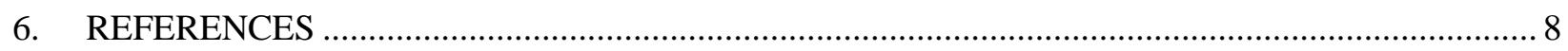





\section{LIST OF FIGURES}

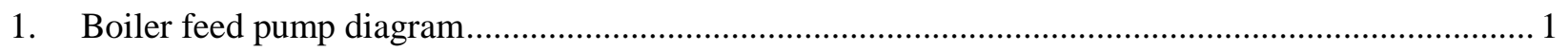

2. Photographs of test position 1 (boiler feed pump discharge) …................................................... 3

3. System installation at Kingston Fossil Plant ............................................................................. 3

4. Photograph of test position 2 (boiler feed pump suction) ............................................................... 4

5. Software display of power spectral density (PSD) and cross power spectral

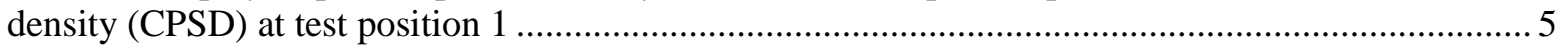

6. Software display of temperature measurements at test position 1 ................................................. 5

7. Software display of power spectral density (PSD) and cross power spectral

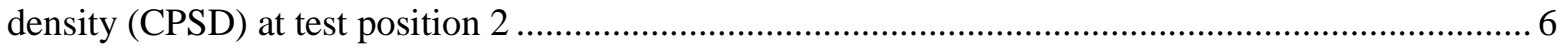

8. Software display of power spectral density (PSD) and cross power spectral

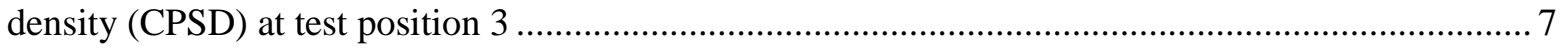

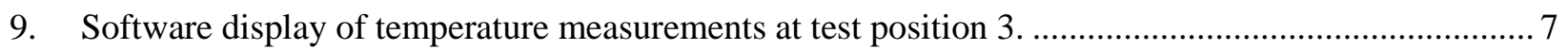





\begin{abstract}
This report summarizes off-site testing performed at the Tennessee Valley Authority Kingston Fossil Plant. This location was selected as a valid off-site test facility because the environment is very similar to the expected industrial nuclear power plant environment. This report will discuss the electromagnetic interference discovered in the environment, the removal technique validity, and the results from the measurements.
\end{abstract}

\title{
1. KINGSTON FOSSIL PLANT ENVIRONMENT
}

The Tennessee Valley Authority Kingston Fossil Plant (KFP) is located on Watts Bar Reservoir on the Tennessee River near Kingston, Tennessee. KFP is a coal-burning power plant. Its nine units boast a summer net capacity of 1,390 MW and can generate about 10 billion $\mathrm{kW}-\mathrm{Hr}$ a year [1]. This facility houses boilers, pumps, scrubbers, and many other pieces of equipment that produce mechanical vibrations and electromagnetic interference (EMI). Two locations were selected as valid locations for Johnson noise thermometry (JNT) measurement. The first location was at the feed pump discharge of a boiler. The second location was at the boiler's feed pump suction (Figure 1). The feed pump discharge is a warm location averaging around $425 \mathrm{~K}$, and the feed pump suction averages around $410 \mathrm{~K}$.

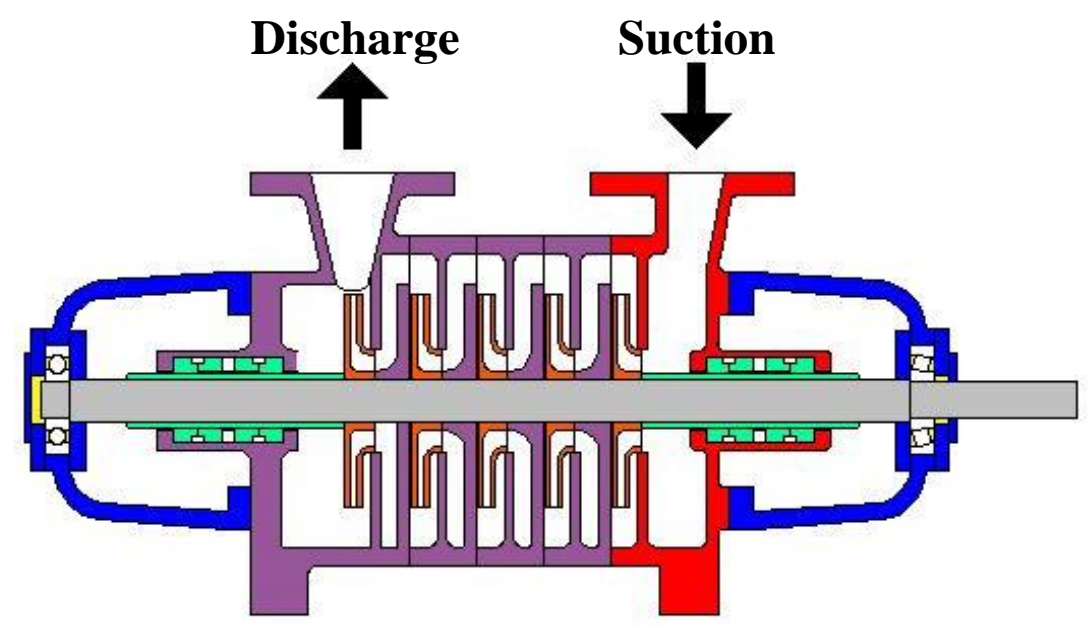

Figure 1. Boiler feed pump diagram.

Measurements at each of these locations indicated a variety of EMI in the surrounding environment. The results from these measurements are discussed later in this document.

\section{SOURCES OF ELECTROMAGNETIC INTERFERENCE AND ITS IMPACT}

As discussed in previous reports [2]-[6], EMI has a great impact on JNT measurements. Various sources, such as power lines, lights, computer power supplies, cathode-ray tubes, cell phones, motors and pumps, and data lines (e.g., the Ethernet), emit EMI [2], which can prevent accurate temperature measurement. The sources of EMI studied for this project were categorized as either transient or periodic. Transient EMI is a signal that begins, persists for some time, and then stops. Periodic EMI is a signal that is always present and repeats a pattern indefinitely. Transient EMI is a substantial deviation in the acquired signal from the expected noise voltage of the sensor. Because the sensor noise voltage has a Gaussian distribution within a known limit and a mean value equal to zero, any variations twice the standard deviation of the mean value are the result of transient EMI. The two methods used to detect transient EMI 
in this study, the rejection method and the subtraction method, use a windowing technique to detect the transient EMI. The sensor noise acquired is in blocks of data that make up 16 subblocks of data. Each subblock of data is evaluated with the windowing process, and if transient EMI is present, the subblock is replaced with the mean value.

Removing periodic EMI requires a different technique from that for transient EMI. In the rejection method, a "despiking" algorithm detects and rejects periodic EMI spikes. This algorithm is nonlinear and time-dependent. It also can have leakage problems [3]. For these reasons, a second method, the subtraction method, was developed. The subtraction method acquires a frequency response of the EMI environment through an antenna signal. This becomes evident in the discussion of the measurement results (Sect. 4).

\section{ELECTROMAGNETIC INTERFERENCE ENVIRONMENT AT KINGSTON FOSSIL PLANT}

Laboratory testing of EMI removal techniques has been discussed in previous reports [2]-[6]. Laboratory testing is a good proof of concept, but such environments are relatively clean of EMI. To further test the abilities of the EMI removal techniques developed as part of this project, testing was moved to two offsite locations. The first of these test locations was Sandia National Laboratories in Albuquerque, New Mexico (Sandia). Sandia's Brayton cycle was selected because it is a relatively similar EMI environment to that of a nuclear power plant. Several resistance temperature detectors (RTDs) were strategically placed at different locations on a Brayton cycle at Sandia. Brayton cycle technology is a highly efficient thermal-to-electrical power conversion system [6]. The second location was KFP. At the plant, two locations were selected for this experiment. At the first location, shown in Figure 2, the RTD was installed in the feed pump discharge of a boiler.

The instrumentation was installed very close to the RTDs to minimize cabling running through the plant. A 10 m yellow cable, visible in Figure 3, was used in all JNT measurements. The front end electronics and laptop were left on carts due to water on the floor of the facility. The JNT instrument system was in the vicinity of high voltages, light ballasts, two boilers, several pumps, air conditioning units, chillers, etc. The results from this measurement are discussed in Sect. 4. 

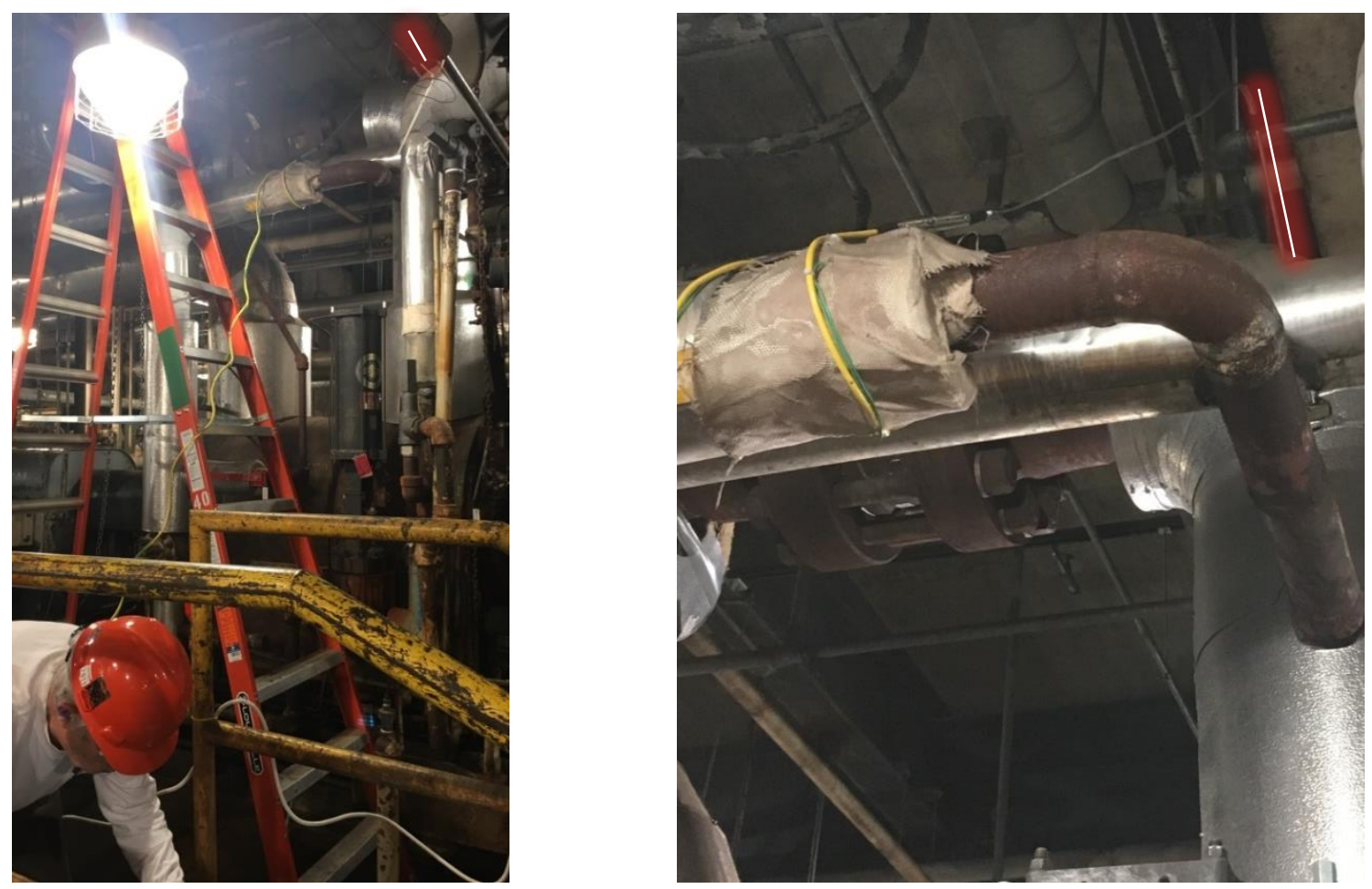

Figure 2. Photographs of test position 1 (boiler feed pump discharge).

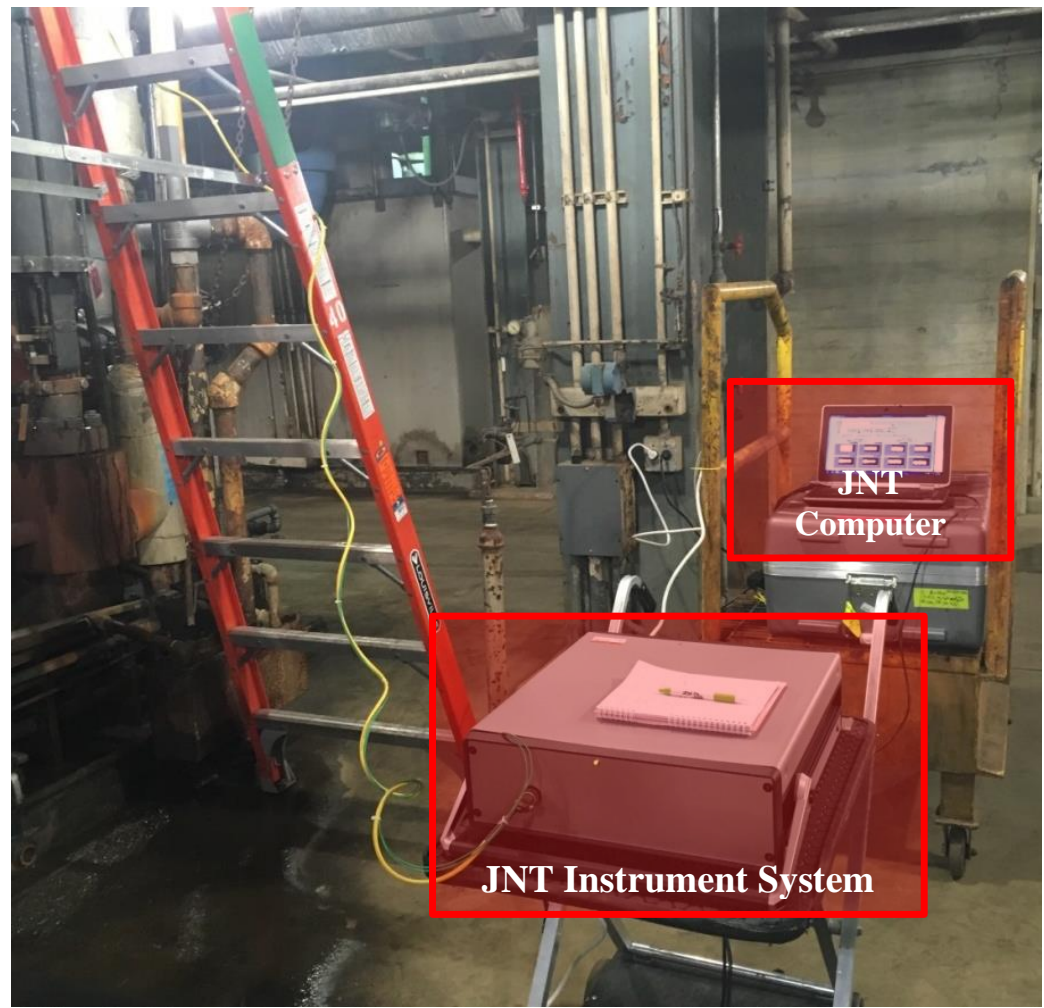

Figure 3. System installation at Kingston Fossil Plant. 
For the second test position at KFP, an RTD was installed at the feed pump suction of a boiler (Figure 4). The EMI noise sources at this position, high voltages, light ballasts, two boilers, several pumps, air conditioning units, chillers, etc., are very similar to those at test position 1 (Figure 2). Because testing at test position 2 was cut short due to unscheduled maintenance to the boiler, a third measurement was taken at another boiler's feed pump discharge (test position 3 ). The results for these two test locations are discussed in Sect. 4.

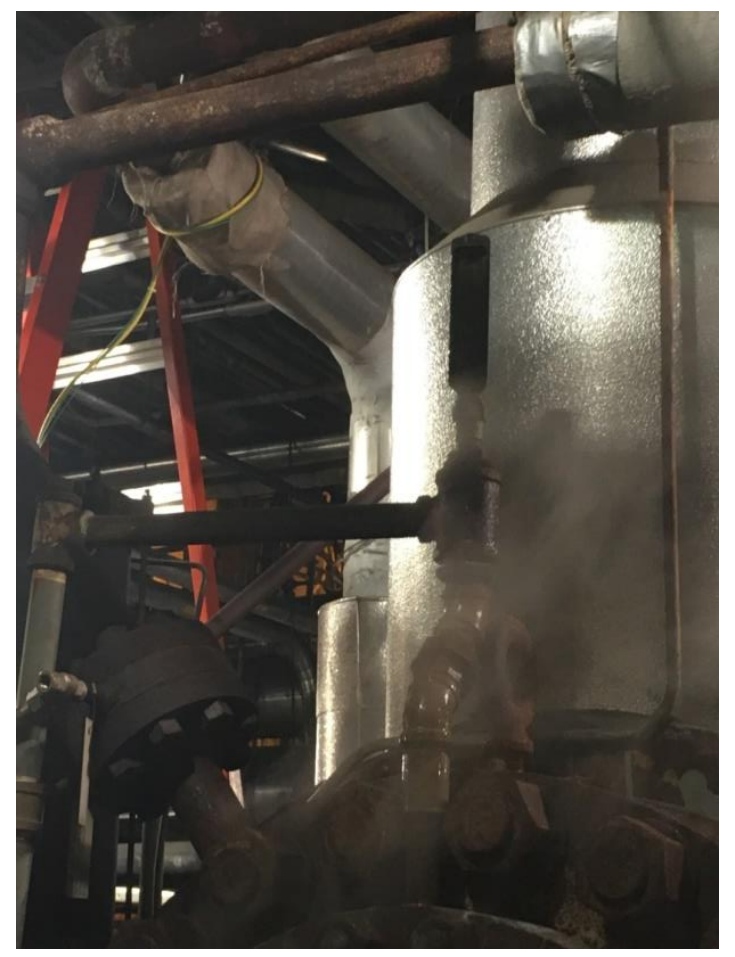

Figure 4. Photograph of test position 2 (boiler feed pump suction).

\section{ELECTROMAGNETIC INTERFERENCE SPECTRAL RESULTS}

The EMI spectral results are a summary of the testing at KFP. The first measurement at the boiler's pump discharge indicated large amounts of EMI noise across a broad band of frequencies (Figure 5).The EMI noise sources at $47 \mathrm{kHz}$ and $63 \mathrm{kHz}$ were expected as they were present in previous measurements. The additional EMI at $37 \mathrm{kHz}, 18 \mathrm{kHz}, 20 \mathrm{~Hz}-8 \mathrm{kHz}$, and $10 \mathrm{kHz}$ were due to EMI noise sources inside the facility. While conclusions about the sources of EMI cannot be made, based on the experimental results it can be concluded that the system is capable of surviving large amounts of EMI. The desired resistor power spectral density (RPSD) waveform is flat at an offset equal to the RPSD. Both the subtraction and rejection methods, discussed in previous reports [2]-[6], report a flat RPSD equal to $1.8 \mathrm{E}-18 \mathrm{~V}^{2} / \mathrm{Hz}$. The temperature computation depends heavily on an accurate measurement of the cross power spectral density between channel 1 and channel $2\left[\mathrm{G}_{12}(\mathrm{f})\right]$, the cross frequency response between channel 1 and channel 2 $\left[\mathrm{H}_{12}(\mathrm{f})\right]$, and the resistor power spectral density [G $\left.\mathrm{G}_{\mathrm{Rs}}(\mathrm{f})\right]$ [7] [refer to Eq. (1)]. If EMI is not properly removed, this computation will be incorrect.

$$
T_{s}=\left\lfloor\frac{G_{12}(f)}{H_{12}(f)}-G_{R c}(f)\right\rceil \times\left\lfloor\frac{1}{2 k R_{s}}\right\rceil
$$




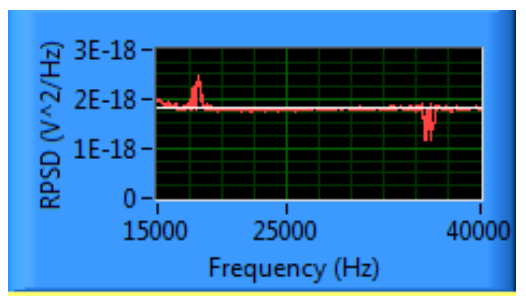

Resistor PSD using Subtraction Method

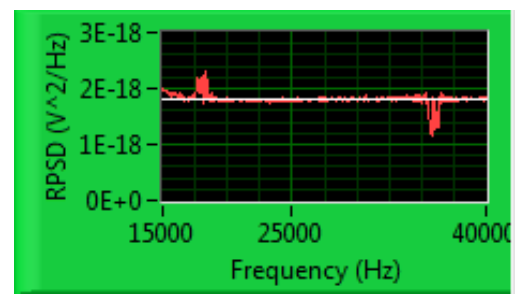

Resistor PSD using Rejection Method

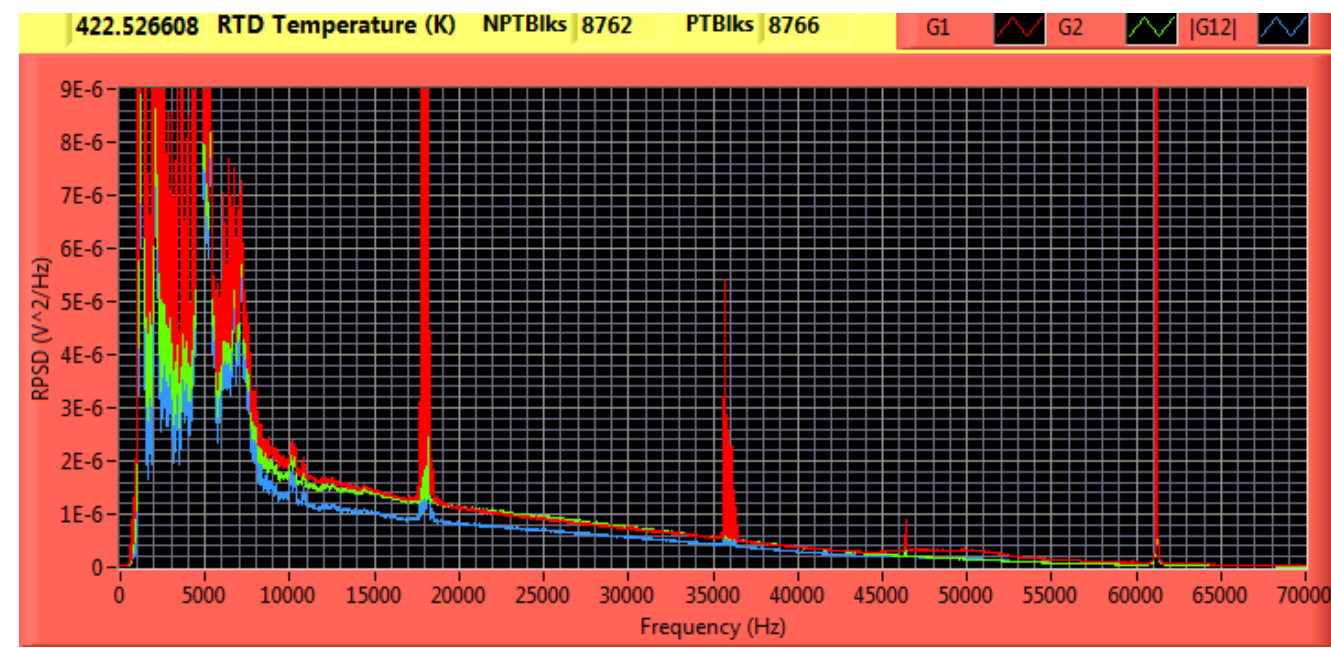

PSD of Channel 1 (RED), PSD of Channel 2(GREEN), and CPSD between Channels 1 \& 2 (BLUE)

Figure 5. Software display of power spectral density (PSD) and cross power spectral density (CPSD) at test position 1.

The JNT temperatures (green and red) were plotted along with the real-time dc temperature (white) (Figure 6). The JNT temperatures not only have a very low error (less than $0.5 \%$ ), they also track as the temperature is changing. This is a very reassuring result.

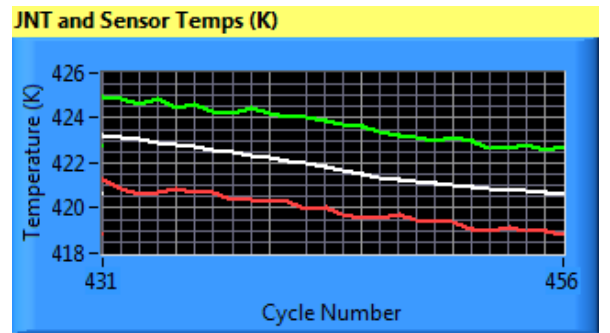

Temperature Output using Subtraction Method

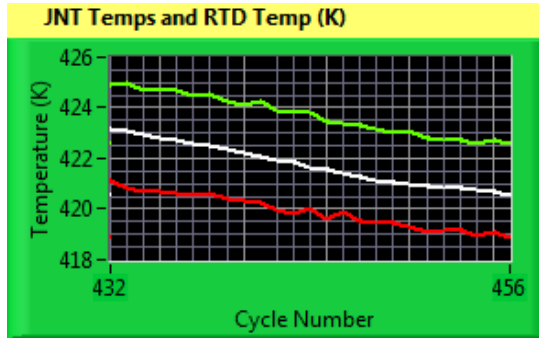

Temperature Output using Rejection Method

Figure 6. Software display of temperature measurements at test position 1.

The second measurement at the boiler's feed pump suction ran for less than half the time of the first measurement. Recall from previous reports [2]-[6] that this measurement takes a little time to settle, so the longer the measurement runs, the better the results from the calculations. The results from these measurements are shown in Figure 7. 


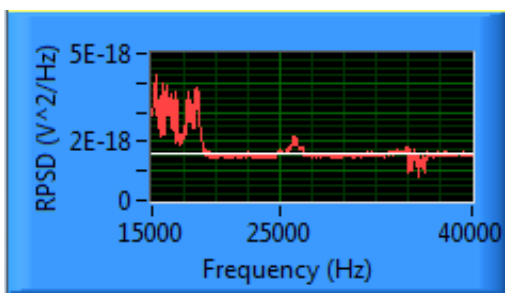

Resistor PSD using Subtraction Method

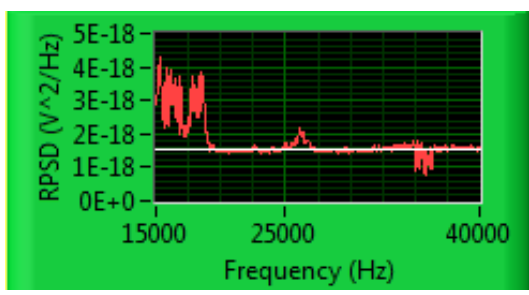

Resistor PSD using Rejection Method

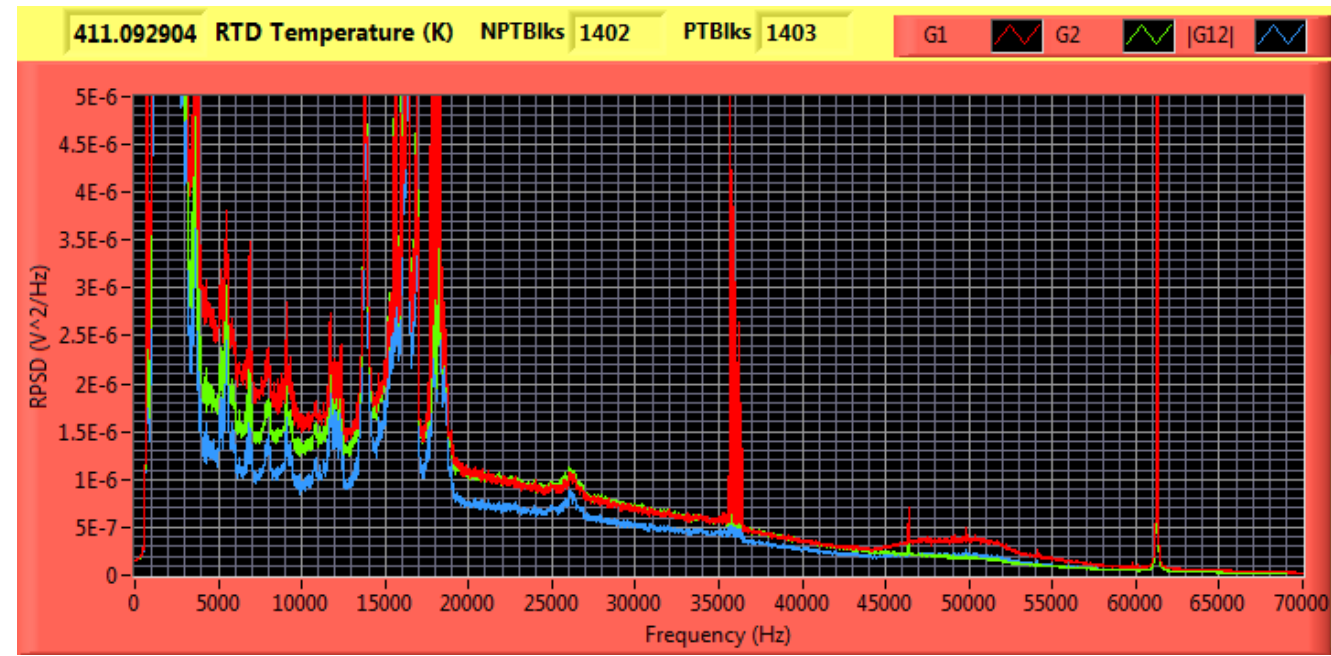

PSD of Channel 1 (RED), PSD of Channel 2(GREEN), and CPSD between Channels 1 \& 2 (BLUE)

Figure 7. Software display of power spectral density (PSD) and cross power spectral density (CPSD) at test position 2.

Note the large amount of low frequency EMI noise from $20 \mathrm{~Hz}-18 \mathrm{kHz}$, the additional EMI at $27 \mathrm{kHz}$, and that channel 1 is picking up broad noise centered around $50 \mathrm{kHz}$. Even with the added EMI and the short runtime, the system was able to survive the measurement environment with only a small error in temperature computation.

After the boiler at test position 2 was shut down for maintenance, the RTD was relocated to a different boiler feed pump discharge (test position 3). The results from these measurements show an increase in EMI in the environment (Figure 8). This might be due to the maintenance performed in the same area. 


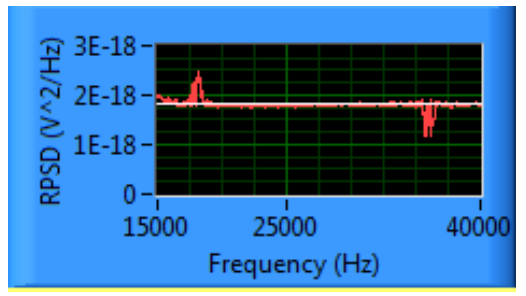

Resistor PSD using Subtraction Method

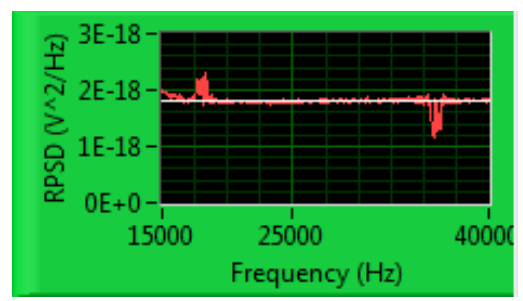

Resistor PSD using Rejection Method

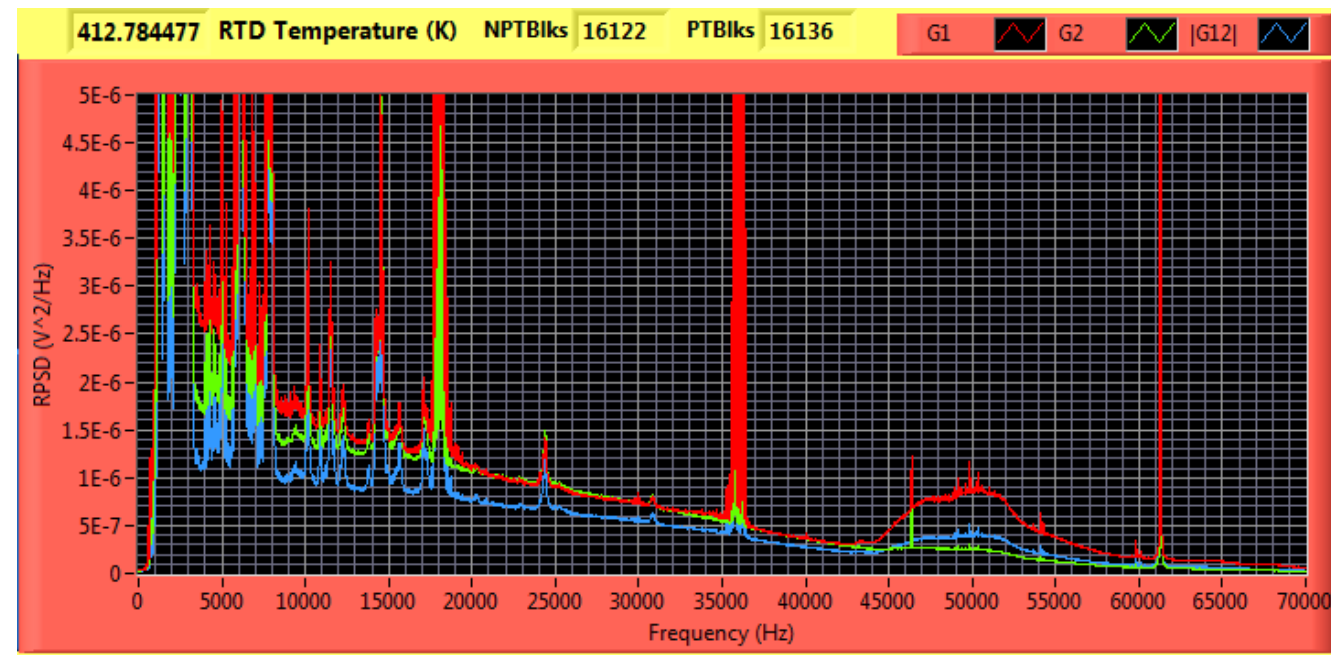

PSD of Channel 1 (RED), PSD of Channel 2(GREEN), and CPSD between Channels $1 \& 2$ (BLUE)

Figure 8. Software display of power spectral density (PSD) and cross power spectral density (CPSD) at test position 3.

Note the continued large amount of low frequency EMI noise in the $20 \mathrm{~Hz}$ to $18 \mathrm{kHz}$ range, the additional EMI at $24 \mathrm{kHz}$, and that channel 1 is picking up broad noise centered around $50 \mathrm{kHz}$. The NPJNT (nonpilot-tone JNT [2]-[7]) temperature computed using the subtraction method has a very low error rate $(0.5 \%)$ (Figure 9). However, the rejection method is unable to compute JNT temperatures equivalent to the real-time dc temperature. The white waveform is the real-time temperature measurement (Ts), the red waveform is the pilot-tone JNT (PTJNT), and the green waveform is the non-pilot tone JNT (NPTJNT).

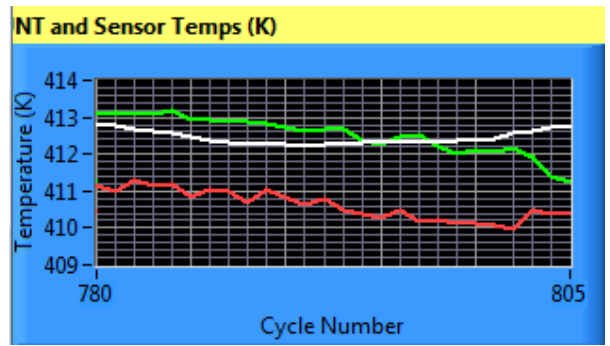

Temperature Output using Subtraction Method

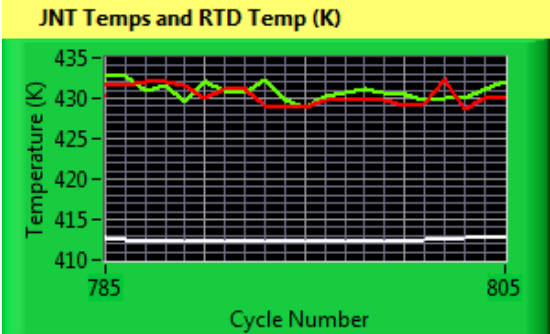

Temperature Output using Rejection Method

Figure 9. Software display of temperature measurements at test position 3 where white $=$ Ts, red $=$ PTJNT, and green $=$ NPTJNT. 
Measurements at all three locations were taken over a single day. Ideally, the system will run for several days, months, or even years, allowing for a short calibration period and then the measurement period. Since the system survived in this industrial environment, it will also survive in a nuclear power plant environment.

\section{CONCLUSION}

In most environments the subtraction and rejection methods operate as expected. However, in extreme EMI environments, the subtraction method outperforms the rejection method. The software operates both methods simultaneously, so discrepancies in temperature computation are not an issue. Based on testing the system in two industrial facilities, first Sandia [6] and then KFP, it can be concluded that the system will survive in harsh environments such as nuclear power plants. When EMI is properly removed, the temperature computations deliver an accurate and repeatable temperature output.

\section{REFERENCES}

[1] https://www.tva.com/Energy/Our-Power-System/Coal/Kingston-Fossil-Plant

[2] N. Dianne Bull Ezell, Charles L. Britton, Jr., and Michael Roberts, Report of the EMI Testing of Johnson Noise Thermometry System, ORNL/TM-2014/237, SMR/ICHMI/ORNL/TR-2013/01, June 2014.

[3] Charles L. Britton, Jr., Michael Roberts, Nora D. Bull, Lou Qualls, and David E. Holcomb, Johnson Noise Thermometry Requirements, ORNL/TM-2013/2, SMR/ICHMI/ORNL/TR-2013/01, January 2013.

[4] Charles L. Britton, Jr., Michael Roberts, Nora D. Bull, , David E. Holcomb, and Richard T. Wood, Johnson Noise Thermometry for Advanced Small Modular Reactors, ORNL/TM-2012/346, SMR/ICHMI/ORNL/TR-2012/01, September 2012.

[5] Charles L. Britton, Jr., Nora D. Bull, Michael Roberts, Amplifiers Module Prototype for the Johnson Noise Thermometry System, ORNL/TM-2013/192, SMR/ICHMI/ORNL/TR-2012/03, May 2013.

[6] Charles L. Britton, Jr., N. Dianne Bull Ezell, Michael Roberts, Johnson Noise Thermometry DataAcquisition Backend, ORNL/TM-2013/499, SMR/ICHMI/ORNL/TR-2013/06, October 2013.

[7] N. Dianne Bull Ezell, “An Innovative Approach to Johnson Noise Thermometry by Means of Spectral Estimation.” PhD diss., University of Tennessee, 2016. 